\title{
On the estimation of feasibility of engineering services use by machine-building enterprises
}

\author{
Ramil Mavlioutov ${ }^{1,}{ }^{*}$, Ekaterina Butenko ${ }^{1}$, and Regina Menyailova ${ }^{1}$ \\ ${ }^{1}$ Volgograd State Technical University, 400005 Volgograd, the Russian Federation
}

\begin{abstract}
The article highlights the main advantages of engineering services in the implementation of the project. An approach to the estimation of the engineering console as an additional income received by the customer company as a result of engaging an engineering company is proposed. This approach allows to evaluate the validity of the use of engineering services both by the machine-building enterprises themselves as potential customers and engineering companies.
\end{abstract}

\section{Introduction}

The imperative of the development of modern economy is the permanent accelerating growth of the level of science-intensive production, goods, works and services. As a result, the importance of engineering activity is growing in the context of the economic relations of industrial enterprises. In the first place, this trend is affected by the machine-building enterprises. The theory and practice of engineering business does not provide for a single category of "engineering service". Within the framework of this article, an engineering service is understood as a complex of professional services of a commercial nature provided by engineers at all stages of the technological chain of creating a new facility or developing equipment (converting new scientific knowledge into a technical product or a new industrial facility). This complex can include both the whole range of services and individual components [1]. The engineering company is understood as a professional intermediary uniting fundamental and applied science, design and research institutes and manufacturing enterprises, integrating and coordinating the work within the framework of the implementation of new technological projects [2].

The current situation is characterized by the emergence of the practice of applying advanced approaches to managing the operation of engineering companies in Russia. There have been significant changes in the sphere of increasing trade in complex types of equipment against the background of the increasing globalization of economic relations. This necessitates special knowledge for solving both technological and organizational issues. This is the guarantee of the competitiveness of machine-building enterprises in the field of growing struggle for an ever more demanding consumer [3]. At the same time, among the peculiarities of the current situation, first of all, it is necessary to allocate a small motivation in machine- building enterprises to use the services of engineering companies due to low efficiency and low possibility of raising it. There is a contradiction of high input costs for attracting an engineering company with the expected impact.

Due to the lack of a formalized approach that allows to assess the estimation of feasibility of engineering services use within the framework of this article we are going to present the results of our developments on this subject. For this purpose, the study is aimed at solving problems: clarifying the conceptual instrument in terms of determining the economic effect of engaging the engineering company; highlighting the main advantages of engaging an engineering company; determining the impact of engineering services of each of the identified advantages on the amount of revenue of the customer company, as well as their total impact.

A number of researchers note the high potential of engaging engineering companies [4-9]. Here are its main components.

1. Reduction of project implementation deadlines.

2. End-to-end technological responsibility. Within the traditional approach, there is an accumulation of deviations from technological requirements, which leads to a drop in the company's income.

3. High quality, genetics of technical solutions.

4. Reducing the cost of risks. The engineering company plans in advance measures to prevent and mitigate the consequences of risks.

5. Application of project financing. Financial institutions interact on the basis of the most favourable conditions (lowering interest rates, shifting from collateral financing to project one). Long-term contracts, encourage counterparties to cooperate with the use of all kinds of discounts.

In order to identify the income received by the contracting company as a result of engaging the engineering company, we propose the use of the concept

* Corresponding author: ramil-2002@mail.ru 
of an engineering console. (abridged from English consolidated annuity).

The appearance of the engineering console is due to the following main factors: application of the competencies inherent in the engineering company, throughout the life cycle of the implemented project; the unique nature of the competencies used by the engineering company; priority of suppliers and contractors with a high degree of contractual terms. The cumulative effect of the mutual influence of these factors creates a positive impact on the profitability of the implemented project and, therefore, the investment attractiveness.

Due to the fact that projects involving the engineering company tend to have a significant implementation period, measured in several years, the time factor is mandatory [10]. Net present value (NPV) is the most widely used indicator to estimate the projects taking into account the time factor. Taking into account our definition of the engineering console category (hereinafter - EC), as well as the specifics of its formation, we propose in this article to calculate the EC as the difference between the NPV of the project involving the engineering company (hereinafter - the $N P V_{E}$ ) and the NPV of the project excluding its involvement (hereinafter - $N P V_{0}$ ).

$$
E C=N P V_{E}-N P V_{0}
$$

The value of the net present value of the project is determined by the well-known formula:

$$
N P V=\sum_{i=1}^{n} \frac{N C F_{i}}{(1+I)^{i}}-\sum_{i=1}^{n} \frac{I n v_{i}}{(1+I)^{i}},
$$

where $N C F_{i}$ is the net cash flow of the $i$-period of the investment project,

$I n v_{i}$ are investments, attached to the $i$-period of the investment project,

$I$ is the cost of capital attracted for the implementation of the investment project,

$n$ is the period of implementation of the investment project (the calculation level).

To concretize and implement the subsequent analysis it is expedient to present the formula (2) in the form:

$$
\begin{aligned}
& N P V=\sum_{i=1}^{n} \frac{\left(1-I T_{i}\right)\left(P_{i} Q_{i}-V C_{i}-F C_{i}\right)}{(1+I)^{i}}- \\
& -\sum_{i=1}^{n} \frac{\left(1-I T_{i}\right)\left(M P_{i}+O E_{i}\right)}{(1+I)^{i}}-\sum_{i=1}^{n} \frac{I n v_{i}}{(1+I)^{i}}
\end{aligned}
$$

where $I T_{i}$ is the corporate income tax rate,

$P_{i}$ is the unit price (monetary units a piece)

$Q_{i}$ is the sales volume in physical terms,

$V C_{i}$ are variable costs in the cost of production,

$F C_{i}$ are constant costs in the cost of production,

$M P_{i}$ are interest payments within the framework of loan servicing,

$O E_{i}$ are other expenses attributable to the financial result of the organization.
World experience of functioning of engineering companies allows to formulate the advantages provided by their attraction:

1. Reduction of the project implementation period;

2. Risk reduction;

3. Generation of engineering solutions;

4. The high level of business reputation of the engineering company is correlated to the companycustomer.

It is necessary to consider in detail the impact of the engagement of the engineering company on the components of the NPV.

\section{Reduction of the project implementation period}

The use of services of engineering companies ensures the combination of the implementation of a number of processes, which provides an opportunity to reduce the duration of the pre-investment stage and the investment stage. Together, this enables the customer company to begin generating profits at an early stage through an early entry into the operational phase [11]. From this we can conclude that $\mathrm{nE}<\mathrm{n} 0$. If we assume that the other conditions are equal, the investment project with a shorter implementation period, has a higher NPV. Here it is possible to identify the emergence of the engineering console, due to the reduction in the duration of the investment project.

\section{Risk reduction}

In the process of estimation NPV, one of the determining factors is the value of the capital cost involved in the implementation of the investment project. The implementation of any investment project implies the existence of a temporary lag between the application of resources and the resulting output, which may result in a change in the deadlines of the project. This causes the emergence of a risk category. Accounting for the risks that accompany the investment project, transpose the investors' preferences. Due to the fact that investors objectively seek to minimize risks, a project with lower risks will be more preferable. The consequence of the latter one is the rise in price of capital as the risks of the implemented project increase [12]. At the same time, risks have a direct impact on the elements of the calculation of the NPV. Thus, we think that is not correct to offset risks solely on the cost of capital. In this regard, it seems necessary to classify the risks accompanying the implementation of the investment project and which are taken into account in the estimation of the NPV. A common feature is to divide the risks of the investment project by sources of their origin into internal and external ones [13].

With reference to an industrial enterprise, the following risks are included in the number of accompanying internal risks:

the risk of inconsistency in the qualifications of personnel in those jobs that they are engaged in. It causes the potential growth of fixed and variable 
expenses as a consequence of the adoption of incorrect, untimely and unjustified management decisions, poor quality of the products. We denote it as $R_{s t}$.

production risk due to technological processes. This risk is caused by the possible failure of production equipment due to improper maintenance, operation or negligence. The consequence of this is the growth of fixed expenses, as well as the other ones attributable to the financial result. We denote this risk as $R_{t}$.

risk of providing the enterprise with financial resources. It is caused by fluctuations in the value of money, as a consequence of inflationary processes, changes in the Central Bank's discount rate and the exchange rate of the national currency relatively to foreign currencies. As a result, it is possible to depreciate the available funds at the disposal of the enterprise, as well as increase the cost of attracting external financing. The consequences of this are the increase of variable expenses, fixed expenses, as well as interest payments within the framework of loan servicing and other expenses attributable to the financial result. We denote this risk as $R_{m}$.

We include the following risks in the risks of external order accompanying the investment project:

risk of disruption in the supply of materials. This risk is caused by possible fraud, the lack of technical ability to produce the necessary materials, the supplier's decision to change the terms of delivery (up to the termination of the contract), accidents in transport. As a result, fixed expenses, as well as other expenses attributable to the financial result, are growing. We denote this risk as $R_{S}$. risk of competition. It is caused by the possible entry of products to the market by competing enterprises, which largely satisfies the needs of consumers, as well as the use of uncivilized forms of competition (misinformation of consumers, compromising goods, pressure on suppliers and banks, etc.). This risk leads to a decrease in prices and sales. Denote this risk as $R_{r}$.

risk of force majeure. Because of their nature, unforeseen events of this kind (natural disasters, wars, epidemics) generate other expenses attributable to the financial result. Denote this risk as $R_{f}$.

risk of deterioration of market conditions. This risk is generated by problems in the sales sphere: incorrect selection of the sales market, incomplete information about competitors, slow introduction of innovations into production. This risk carries the risk of slowing the pace of sales, accompanied by a drop in selling prices. Denote this risk as $R_{c}$.

These risks affect not only the implementation of the forecast of net cash flow for a certain period of the investment project, but also in determining the cost of capital involved in the implementation of the investment project, I. Therefore, we should cite the risk of raising the cost of capital, which is denoted as $R_{I}$.

So, relying on the formula (3), the total influence exerted on the NPV by the described risks can be represented in next formula (4). Further, let us single out the risk factors characteristic for the components of this formula (4):

$R C_{1}$ is the risk factor for increasing the cost of capital $I$;

$R C_{2}$ is the risk factor for reducing the unit price $P_{i}$;

$R C_{3}$ is the risk factor for decreasing sales $Q_{i}$;

$R C_{4}$ is the risk factor for the growth of variable expenses in the cost of production $V C_{i}$;

$R C_{5}$ is the risk factor for increasing fixed expenses in the cost of production $F C_{i}$;

$R C_{6}$ is the risk factor for the growth of interest payments within the framework of the $M P_{i}$ loan service;

$R C_{7}$ is the risk factor for the increase in other expenses attributable to the financial result of the organization, $O E_{i}$. So, the total influence exerted on the $N P V$ can be represented as:

$$
\begin{gathered}
N P V=\sum_{i=1}^{n} \frac{\left(1-I T_{i}\right)\left(R_{r} R_{c} P_{i} Q_{i}\right)}{\left(1+R_{I} I\right)^{i}}- \\
-\sum_{i=1}^{n} \frac{\left(1-I T_{i}\right)\left(R_{s t} R_{m} V C_{i}+R_{s t} R_{t} R_{m} R_{s} F C_{i}\right)}{\left(1+R_{I} I\right)^{i}}- \\
-\sum_{i=1}^{n} \frac{\left(1-I T_{i}\right)\left(R_{m} M P_{i}+R_{t} R_{m} R_{s} R_{f} O E_{i}\right)}{\left(1+R_{I} I\right)^{i}}- \\
-\sum_{i=1}^{n} \frac{I n v_{i}}{\left(1+R_{I} I\right)^{i}}
\end{gathered}
$$

By means of the allocated risk factors, formula (4) can be transformed into:

$$
\begin{gathered}
N P V= \\
=\sum_{i=1}^{n} \frac{\left(1-I T_{i}\right)\left(\left(1-R C_{1}\right)\left(1-R C_{2}\right) P_{i} Q_{i}\right)}{\left(1+\left(1+R C_{1}\right) I\right)^{i}}- \\
-\sum_{i=1}^{n} \frac{\left(1-I T_{i}\right)\left(\left(1-R C_{4}\right) V C_{i}\right)}{\left(1+\left(1+R C_{1}\right) I\right)^{i}}- \\
-\sum_{i=1}^{n} \frac{\left(1-I T_{i}\right)\left(\left(1+R C_{5}\right) F C_{i}\right)}{\left(1+\left(1+R C_{1}\right) I\right)^{i}}- \\
-\sum_{i=1}^{n} \frac{\left(1-I T_{i}\right)\left(\left(1+R C_{6}\right) M P_{i}\right)}{\left(1+\left(1+R C_{1}\right) I\right)^{i}}- \\
-\sum_{i=1}^{n} \frac{\left(1-I T_{i}\right)\left(\left(1+R C_{7}\right) O E_{i}\right)}{\left(1+\left(1+R C_{1}\right) I\right)^{i}}- \\
-\sum_{i=1}^{n} \frac{I n v_{i}}{\left(1+\left(1+R C_{1}\right) I\right)^{i}}
\end{gathered}
$$

Taking in the investment project of the engineering company allows to reduce the risks accompanying its implementation. This is due to the presence of a significant level of competence in engineering companies, based on practical experience. In addition, a positive contribution is made by the possession of engineering companies by a systematic array of data on potential risks, the degree of their destructive influence and the possibility of prevention $[14,15]$. Here, it is possible to identify the emergence of an engineering console, caused by a reduction in the risks of an investment project.

\section{Generation of engineering solutions}


At the investment stage and the operational stage of the project implementation, the possession of an engineering company with competencies and accumulated knowledge allows it to choose the optimal solutions in terms of the choice of technologies, equipment, achieving the specified quality at minimum expenses from the point of technical and economic characteristics [16]. This is manifested in the following: an increase in the unit price and sales volume, accompanied by a decrease in the cost price in terms of variable expenses (at the investment stage); decrease in the amount of investments applied (at the investment stage).

Accounting for the effect of generating engineering solutions by introducing in the formula (3) the effect of the generation of engineering solutions $C_{g}$ allows us to provide a general effect on the amount of net present value as:

$$
\begin{gathered}
N P V=\sum_{i=1}^{n} \frac{\left(1-I T_{i}\right)\left(\left(1+C_{g}\right) P_{i} Q_{i}\right)}{(1+I)^{i}}- \\
-\sum_{i=1}^{n} \frac{\left(1-I T_{i}\right)\left(\left(1-C_{g}\right) V C_{i}+F C_{i}\right)}{(1+I)^{i}}- \\
-\sum_{i=1}^{n} \frac{\left(1-I T_{i}\right)\left(M P_{i}+O E_{i}\right)}{(1+I)^{i}}- \\
-\sum_{i=1}^{n} \frac{\left(1-C_{g}\right) I n v_{i}}{(1+I)^{i}}
\end{gathered}
$$

Here it is possible to identify the emergence of an engineering console, caused by the generation of engineering solutions to the investment project.

\section{The high level of business reputation of the engineering company is correlated to the company-customer}

The participation of an engineering company with a business reputation and established relationships with credit institutions provides the opportunity to reduce the cost of financing the project. The reduction of the cost of capital involved in the implementation of the investment project will lead to decrease of interest payments within the framework of debt servicing [17]. The introduction in the formula (3) of the image coefficient of the engineering company $C_{i m g}$ allows to determine the impact on the NPV of this advantage of the engineering company:

$$
\begin{gathered}
N P V=\sum_{i=1}^{n} \frac{\left(1-I T_{i}\right)\left(P_{i} Q_{i}-V C_{i}-F C_{i}\right)}{\left(1+\left(1-C_{i m g}\right) I\right)^{i}}- \\
-\sum_{i=1}^{n} \frac{\left(1-I T_{i}\right)\left(\left(1-C_{i m g}\right) M P_{i}+O E_{i}\right)}{\left(1+\left(1-C_{i m g}\right) I\right)^{i}}- \\
-\sum_{i=1}^{n} \frac{I n v_{i}}{(1+I)^{i}}
\end{gathered}
$$

Here you can identify the origin of the engineering console, due to the high level of business reputation of the engineering company.
The cumulative effect exerted on the net present value of the investment project by four advantages of involving in its implementation an engineering company can be represented as:

$$
\begin{gathered}
N P V= \\
=\sum_{i=1}^{n} \frac{\left(1-I T_{i}\right)\left(1+C_{g}\right)\left(1-R C_{1}\right)\left(1-R C_{2}\right) P_{i} Q_{i}}{\left(1+\left(1-C_{i m g}\right)\left(1+R C_{1}\right) I\right)^{i}}- \\
-\sum_{i=1}^{n} \frac{\left.\left(1-I T_{i}\right)\left(1-C_{g}\right)\left(1-R C_{4}\right) V C_{i}\right)}{\left(1+\left(1-C_{i m g}\right)\left(1+R C_{1}\right) I\right)^{i}}- \\
-\sum_{i=1}^{n} \frac{\left(1-I T_{i}\right)\left(1+R C_{5}\right) F C_{i}}{\left(1+\left(1-C_{i m g}\right)\left(1+R C_{1}\right) I\right)^{i}}- \\
-\sum_{i=1}^{n} \frac{\left(1-I T_{i}\right)\left(1-C_{i m g}\right)\left(1+R C_{6}\right) M P_{i}}{\left(1+\left(1-C_{i m g}\right)\left(1+R C_{1}\right) I\right)^{i}}- \\
-\sum_{i=1}^{n} \frac{\left(1-I T_{i}\right)\left(1+R C_{7}\right) O E_{i}}{\left(1+\left(1-C_{i m g}\right)\left(1+R C_{1}\right) I\right)^{i}}- \\
-\sum_{i=1}^{n} \frac{\left(1-C_{g}\right) I n v_{i}}{\left(1+\left(1+R C_{1}\right) I\right)^{i}}
\end{gathered}
$$

We decided that the engineering console is defined as the difference between the net present value of the investment project with the involvement of the engineering company $\left(N P V_{E}\right)$ and the net present value of the investment project without involving the engineering company $\left(N P V_{0}\right)$. Since the value of $N P V_{0}$ does not change, it is necessary to maximize the $N P V_{E}$, to maximize the size of the engineering console:

$$
\begin{gathered}
N P V_{g}= \\
=\sum_{i=1}^{n} \frac{\left(1-I T_{i}\right)\left(1+C_{g}\right)\left(1-R C_{1}\right)\left(1-R C_{2}\right) P_{i} Q_{i}}{\left(1+\left(1-C_{i m g}\right)\left(1+R C_{1}\right) I\right)^{i}}- \\
-\sum_{i=1}^{n} \frac{\left.\left(1-I T_{i}\right)\left(1-C_{g}\right)\left(1-R C_{4}\right) V C_{i}\right)}{\left(1+\left(1-C_{i m g}\right)\left(1+R C_{1}\right) I\right)^{i}}- \\
-\sum_{i=1}^{n} \frac{\left(1-I T_{i}\right)\left(1+R C_{5}\right) F C_{i}}{\left(1+\left(1-C_{i m g}\right)\left(1+R C_{1}\right) I\right)^{i}}- \\
-\sum_{i=1}^{n} \frac{\left(1-I T_{i}\right)\left(1-C_{i m g}\right)\left(1+R C_{6}\right) M P_{i}}{\left(1+\left(1-C_{i m g}\right)\left(1+R C_{1}\right) I\right)^{i}}- \\
-\sum_{i=1}^{n} \frac{\left(1-I T_{i}\right)\left(1+R C_{7}\right) O E_{i}}{\left(1+\left(1-C_{i m g}\right)\left(1+R C_{1}\right) I\right)^{i}}- \\
-\sum_{i=1}^{n} \frac{\left(1-C_{g}\right) I n v_{i}}{\left(1+\left(1+R C_{1}\right) I\right)^{i}} \rightarrow \max
\end{gathered}
$$

when the constraint is satisfied: $0 \leq i \leq \mathrm{n}$.

So, regardless of expenses caused by the involvement of an engineering company in the implementation of an investment project, there is a positive economic effect, which should be denoted as an engineering console. We have proposed an approach to the definition of an engineering console, which takes into account four advantages for an engineering enterprise from engaging an engineering company: shortening the duration of the 
project; risk reduction; generation of engineering solutions; high level of business reputation of the engineering company is correlated to the companycustomer. The proposed approach can be used in the practice of the functioning of engineering enterprises in the process of making managerial decisions. In addition, the approach is applicable to the activities of the engineering companies themselves as a tool to promote their services. Along with this, the results of the study can be applied in developing approaches to assessing the feasibility of using engineering services by industrial enterprises of various industry affiliations.

\section{References}

1. A.Yu. Glebanova, A.S. Semenov and A.V. Kashirin, Engineering as a special competence in creating a new product: current state and trends, Journal of Economy and entrepreneurship, 56, 843-847 (2015) (in Russian)

2. G.L. Ragatz, R.B. Handfield and T.V. Scannell, Success factors for integrating suppliers into new product development, Journal of Product Innovation Management, 14, 190-202 (1997)

3. K. Clarke, Can engineers lead again? Engineering, 2, 19-20 (2016)

4. P.V. Grigor'ev and Yu.S. Kan, Optimal control of the investment portfolio with respect to the quantile criterion, Automation and Remote Control, 65, 319336 (2004)

5. L. Burneika, Managing changes in product configurations, Solid State Phenomena, 144, 208213 (2009)

6. Z.A. Mingaleva, Structural modernization of economy and innovation development, World Applied Sciences Journal, 20, 1313-1316 (2012)

7. W. Aarseth, A. Rolstadås and B. Andersen, Managing organizational challenges in global projects, International Journal of managing Projects in Business, 7, 103-132 (2013)
8. K.V. Aikhel, Business engineering - managing for sustainable development of enterprises, Science Time, 2, 24-28 (2016) (in Russian)

9. P.V. Krush and I.V. Makaliuk, Study of internal factors influence on transaction expenses of engineering companies, Naukovyi Visnyk Natsionalnoho Hirnychoho Universytetu, 1, 134-143 (2014)

10. E.-H. Ng and N.G. Beruvides, Multiple internal rate of return revisited: frequency of occurrences, Engeeniring Economist, 60, 75-87 (2015)

11. O.O. Orlov, Problems of innovation projects' evaluation in mechanical engineering, Actual Problems of Economics, 163, 43-51 (2015)

12. N.V. Usmanova and N.A. Orlova, The role of transaction costs in risk management of investment projects, Journal of Advanced Research in Law and Economics, 7, 1226-1233 (2016)

13. B. Yermekbayeva and R. Doszhan, Specifics of risk management for small and medium business enterprises, World Applied Sciences Journal, 27, 774-778 (2013)

14. P. Li P, Ch. Li and J. Wan, The comparison and selection of investment projects: a new standatdized risk measure, Engeeniring Economist, 48, 127 (2003)

15. Y. Wang and M. Li, The role of internal audit in engineering project risk management, Procedia Engineering, 24, 689-694 (2011)

16. A.E. Sklyarov and A.Yu. Glebanova, Innovative activity of high-technology companies as assessment and forecasting object, Proceedings of the Voronezh State University of Engineering Technologies, 3, 296-299 (2016) (in Russian)

17. Y.P. Anisimov, Y.V. Zhuravlyov and A. A. Shvets, Analysis of efficiency of innovative projects, Proceedings of the Voronezh State University of Engineering Technologies, 3, 180-185 (2012) (in Russian) 